\title{
Rapid GC-MS confirmation of amphetamines in urine by extractive acylation
}

\author{
Adriaan A.S. Marais, Johannes B. Laurens* \\ Department of Chemistry, University of Pretoria, Pretoria 0002, South Africa
}

\section{A R T I C L E I N F O}

Article history:

Received 26 September 2008

Received in revised form 28 October 2008

Accepted 30 October 2008

Available online $\mathrm{xxx}$

\section{Keywords:}

Extractive acylation

Methcathinone

Amphetamines

Rapid GC-MS

Isotope dilution

\begin{abstract}
A B S T R A C T
Amphetamine and related derivatives are widely abused central- and psychostimulants. Detection of certain derivatives, such as methcathinone, by commonly available immunoassay screening techniques is insufficient. Multi-analyte confirmations for amphetamine type stimulants are therefore required, but traditional gas chromatography-mass spectrometry methods necessitate lengthy analytical procedures with prolonged sample turn-around times. A validated rapid GC-MS assay for urinary confirmation of amphetamine, methamphetamine, methcathinone, ephedrine, norephedrine, methylenedioxyamphetamine, methylenedioxymethamphetamine, methylenedioxyethylamphetamine and N-methyl-1-(3,4 methylenedioxyphenyl)-2-butanamine is reported. The method entailed in situ derivatization of urine specimens by extractive acylation with pentafluoropropionic anhydride, followed by rapid chromatography on a microbore capillary column. Analytes were separated in less than 3 min and quantified simultaneously by selected-ion monitoring using stable isotope substituted internal standards. The total instrument cycle-time was 6 min per sample. The limits of detection were between $1.5 \mathrm{ng} / \mathrm{mL}$ and $6.25 \mathrm{ng} / \mathrm{mL}$ for the various analytes. Intermediate precision and accuracy were in the range of $6.3-13.8 \%$ and $90.5-107.3 \%$ for the respective analytes at the lower limit of quantitation, and between 5.8-12.6\% and $95.4-103.1 \%$ for the high control. Long-term storage of methcathinone positive specimens at $-20{ }^{\circ} \mathrm{C}$ proved insufficient stability of this analyte. The proposed assay is precise and accurate for confirmation of amphetamine and derivatives in urine. The complementary approach of extractive-derivatization and fast GC-MS analysis is especially applicable in routine clinical settings where reduced sample turnaround times are required. Further investigation of cathinone as a possible metabolite of methcathinone is warranted, based on results from analyzed authentic urine samples.
\end{abstract}

(c) 2008 Elsevier Ireland Ltd. All rights reserved.

\section{Introduction}

Stimulant abuse has increased worldwide over the past decade with the classical phenethylamine derivatives amphetamine (AMP, "Speed") and methamphetamine (MET, "Ice") at the forefront. In South Africa, there has been a high incidence of methamphetamine abuse in the Western Cape region since 2003, where it has currently

\footnotetext{
* Corresponding author. Tel.: +27 12420 5442; fax: +27 123192915 .

E-mail address: tim.laurens@up.ac.za (J.B. Laurens). Abbreviations: AMP, amphetamine; MET, methamphetamine; MCA, methcathinone; EPH, ephedrine; PEP, pseudoephedrine; MDMA, methylenedioxymethamphetamine; MDA, methylenedioxyamphetamine; MDEA, methylenedioxyethylamphetamine; MBDB, $N$-methyl-1-(3,4 methylenedioxyphenyl)-2-butanamine; GC-MS, gas chromatography-mass spectrometry; LC-MS/MS, liquid chromatography-tandem mass spectrometry; CT, cathinone; NE, norephedrine; NPE, norpseudoephedrine; HFBA, heptafluorobutyric anhydride; HMMA, 4-hydroxy-3-methoxymethamphetamine; PFPA, pentafluoropropionic anhydride; QC, quality control; IS, internal standard; LLQ lower limit of quantitation; $\mathrm{S} / \mathrm{N}$, signal-to-noise ratio; SIM, selected-ion monitoring; LOD, limit of detection.
}

become the most prevalent drug of abuse, superseding the use of historically more commonly abused substances such as cocaine [1]. In other regions, the synthetic designer drug methcathinone (MCA, "Cat") has risen in popularity, especially amongst youth involved in the so-called club culture. Likely reasons for this trend are due to both the low cost and ease of synthesis of these compounds from standard over-the-counter preparatives, namely ephedrine (EPH) or pseudoephedrine (PEP). Ring substituted derivatives of amphetamine and methamphetamine such as the methylenedioxy designer drugs methylenedioxymethamphetamine (MDMA, "Ecstacy"), methylenedioxyamphetamine (MDA, “Adam"), methylenedioxyethylamphetamine (MDEA, "Eve") and N-methyl-1-(3,4 methylenedioxyphenyl)-2-butanamine (MBDB) represent a lower, yet still significant percentage of abused psychostimulants, especially under recreational drug users.

AMP and MET are potent central nervous system stimulants that produce increased alertness and euphoria [2,3]. MCA has been shown to have similar central stimulant effects as MET [4,5] and is more potent than cathinone (CT) [6], however there is a reported 
greater degree of impaired judgment and inability to concentrate. The metabolism of AMP and most derivatives have been elucidated [7-9] but the complete metabolism and expected half-life of MCA was not documented in any published work at the time of this study. Published urinary excretion profiles for CT and MCA have however appeared $[10,11]$.

Quantitative analyses of amphetamine and associated analogs have been reviewed [9]. Analytical strategies including gas chromatography (GC) [12,13], high performance liquid chromatography (HPLC) [14,15], gas chromatography-mass spectrometry (GC-MS) [10,12,16-21] and liquid chromatography-tandem mass spectrometry (LC-MS/MS) [22,23] have been employed. The majority of samples received by our laboratory are direct confirmation requests by clinicians. Presumptive positive urine samples that result from laboratory screening and workplace point-of-care devices based on immunoassay technology, which are known to be subject to a variety of cross reactivities [24], are also received on a regular basis. CT and MCA are not listed as cross reactants in such amphetamine immunoassay systems, and the potential metabolic products ephedrine $(\mathrm{EPH})$, pseudoephedrine (PEP), norephedrine (NE) and norpseudoephedrine (NPE) are listed at less than $1 \%$ cross reactivity. A high probability therefore exists of MCA abuse going undetected in these screening methods, which calls into question the traditional approach of exclusive confirmation of screen-positive specimens only.

Multi-analyte confirmation for amphetamine type stimulants is therefore a requirement to ensure that a clear picture of possible abuse is realised. Recent work that has focused on such multianalyte procedures has shown their applicability in a routine laboratory setting [21-23]. LC-MS/MS procedures [22,23] have the advantage of decreased work-up time due to the ability to analyse underivatized compounds. These techniques have also shown the ability to adequately separate structural isomers such as NPE and NE [22] with relatively short analysis times, having a reported instrument cycle-time of 8 min per sample [23]. Currently, GC-MS is still the preferred method for forensic confirmation in urine [25] and has the advantage of lower equipment costs. Utilizing a single step extractive-derivatization technique with heptafluorobutyric anhydride (HFBA), it has been shown that derivatization need not be a timely step in GC-MS sample preparation procedures for amphetamines [21]. Aside from direct injection methodologies that may suffer from their own pitfalls such as ion suppression/ enhancement, similar sample preparation times for GC-MS and LC-MS/MS thus exist.

Rapid chromatographic separation with microbore capillary columns [26] and quick temperature gradients [16,27] in fast GC-MS analysis have indicated the possibility of accurate quantitation in relatively short analysis times with adequate resolution between structurally close-related components. Care must, however, be taken in addressing the number of data points that define a chromatographic peak for forensic confirmations in such methodologies [28-30]. Combining extractive-derivatization techniques with fast GC-MS creates an attractive analytical approach for routine confirmations, only if analytes of interest can be sufficiently separated chromatographically and accurately quantified. Compounds of interest for the present work are illustrated in Fig. 1.

The aim of the present work was to develop a rapid extractivederivatization technique for urinary confirmation of AMP, MET,<smiles>CC(N)Cc1ccccc1</smiles>

Amphetamine (AMP)<smiles>CNC(C)C(=O)c1ccccc1</smiles>

Methcathinone (MCA)<smiles>CNC(C)[C@H](O)c1ccccc1</smiles>

Pseudoephedrine (PEP)<smiles>CNC(C)Cc1ccc2c(c1)OCO2</smiles>

MDMA<smiles>CNC(C)Cc1ccccc1</smiles>

Methamphetamine (MET)<smiles>CC(N)C(=O)c1ccccc1</smiles>

Cathinone

(CT)<smiles>CC(N)[C@H](O)c1ccccc1</smiles>

Norpseudoephedrine (NPE)<smiles>CCNC(C)Cc1ccc2c(c1)OCO2</smiles>

MDEA<smiles>CNC(C)C(O)c1ccccc1</smiles>

Ephedrine $(\mathrm{EPH})$<smiles>CC(N)C(O)c1ccccc1</smiles>

Norephedrine

(NE)<smiles>CC(N)Cc1ccc2c(c1)OCO2</smiles>

MDA<smiles>CCC(Cc1ccc2c(c1)OCO2)NC</smiles>

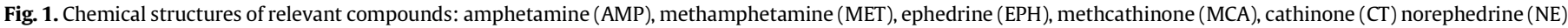

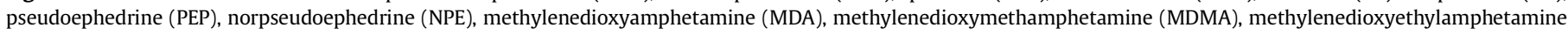
(MDEA), and N-methyl-1-(3,4 methylenedioxyphenyl)-2-butanamine (MBDB). 
MCA, NE, EPH, MDA, MDMA, MDEA and MBDB employing fast GC-MS on a short microbore capillary column.

\section{Materials and methods}

\subsection{Reagents}

All reagents and solvents used were of analytical grade. The following methanolic standards were purchased from Cerilliant (Round Rock, Texas, USA), each at $1 \mathrm{mg} / \mathrm{mL}$ : AMP, MET, MCA, CT, NPE, NE, EPH, PEP, MDA, MDMA, MDEA phentermine (PHM), fenfluramine (FFA,) and 4-hydroxy-3-methoxymethamphetamine (HMMA). Deuterium substituted internal standards were also obtained from the same manufacturer, each at $100 \mu \mathrm{g} / \mathrm{mL}$ in methanol: $\left[{ }^{2} \mathrm{H}_{11}\right] \mathrm{AMP}$, $\left[{ }^{2} \mathrm{H}_{9}\right] \mathrm{MET},\left[{ }^{2} \mathrm{H}_{3}\right] \mathrm{NE},\left[{ }^{2} \mathrm{H}_{3}\right] \mathrm{EPH},\left[{ }^{2} \mathrm{H}_{5}\right] \mathrm{MDA},\left[{ }^{2} \mathrm{H}_{5}\right]$ MDMA and $\left[{ }^{2} \mathrm{H}_{6}\right]$ MDEA. Dichloromethane $\left(\mathrm{CH}_{2} \mathrm{Cl}_{2}\right)$, methanol $\left(\mathrm{CH}_{3} \mathrm{OH}\right)$ and $2,2,3,3,3$-pentafluoropropionic anhydride (PFPA) were purchased from Fluka (Buchs, Switzerland). Sodium hydrogen carbonate $\left(\mathrm{NaHCO}_{3}\right)$ was purchased from Merck (Darmstadt, Germany). Deionized water was obtained from a Milli-Q (Millipore, Bedford, MA, USA) water system. External quality control (EQC) samples (Liquichek ${ }^{\mathrm{TM}}$ ) were obtained from Bio-Rad (Irvine, California, USA).

\subsection{Solutions and biosamples}

Stock solutions of the compounds of interest and internal standards were dissolved in methanol. Initial work solutions containing AMP, MET, MCA, NE, EPH, MDA, MDMA, MDEA and MBDB (solution A) and CT, NPE, PEP, PHM, FFA, and HMMA (solution $B$ ) were appropriately diluted with methanol from stock in the range $125 \mathrm{ng} / \mathrm{mL}$ to $100000 \mathrm{ng} / \mathrm{mL}$ for studying the linearity and selectivity of the assay. After the initial assessments were completed, solutions for calibration and quality control were prepared as follow: A calculated volume of stock solution for each analyte was further diluted in methanol to obtain a calibration working solution of $8000 \mathrm{ng} / \mathrm{mL}$ containing a mixture of AMP, MET, MCA, NE, EPH, MDA, MDMA, MDEA and MBDB. Further serial dilutions were made to obtain final calibration standards of $4000,2000,1000,500,250$ and $125 \mathrm{ng} / \mathrm{mL}$.

A separate quality control (QC) working solution was prepared in a similar manner, but from different lot stock solutions to avoid bias, and further diluted with methanol to yield control solutions that could be spiked in pooled urine (concentrations given below).

The internal standards (IS) were diluted from stock to a concentration of $2000 \mathrm{ng} / \mathrm{mL}$ in methanol. Solutions were stored at $4{ }^{\circ} \mathrm{C}$ in the dark for a maximum of 3 months. Authentic urine specimens were stored at $4{ }^{\circ} \mathrm{C}$ in the dark and analysed within 2 days of reception. Thereafter, aliquots were made and stored frozen at $-20{ }^{\circ} \mathrm{C}$.

\subsection{Equipment}

A Hewlett-Packard 6890 GC system fitted with a Hewlett-Packard 5973 mass selective detector (MSD) (Agilent Technologies, Palo Alto, CA, USA) and a GERSTEL MPS2 injector (Gerstel GmbH \& Co. KG, Müllheim an der Ruhr, Germany) was used for mass spectrometric analysis. A $220 \mathrm{~V}$ oven shroud was installed on the GC. A microbore DB-5 fused-silica capillary column $\left(5 \mathrm{~m} \times 100 \mu \mathrm{m} ; d_{\mathrm{f}}, 0.1 \mu \mathrm{m}\right)$ (Agilent Technologies, Palo Alto, CA, USA) was used to effect fast separation. The MS was tuned monthly with perfluorotributylamine (PFTBA) using the autotune function as per manufacturer's recommendation. Data collection, integration and signal-to-noise ratio $(S / N)$ were performed with HP Chem Station software.

\subsection{GC-MS procedure}

A $1 \mu \mathrm{l}$ volume of derivatized sample was injected in splitless mode with a purge time of $0.1 \mathrm{~min}$ and purge flow of $20 \mathrm{~mL} / \mathrm{min}$. The inlet temperature was set at $280{ }^{\circ} \mathrm{C}$ and helium carrier gas at a constant flow-rate of $0.6 \mathrm{~mL} / \mathrm{min}$. The average velocity was $70 \mathrm{~cm} / \mathrm{s}$. A solvent delay time of $0.9 \mathrm{~min}$ and two-ramp temperature gradient was used. An initial isotherm of $85^{\circ} \mathrm{C}$ was maintained for $0.35 \mathrm{~min}$ and ramped at $62{ }^{\circ} \mathrm{C} / \mathrm{min}$ to a temperature of $115^{\circ} \mathrm{C}$, which was kept for $0.8 \mathrm{~min}$. The second ramp rate was $65^{\circ} \mathrm{C} / \mathrm{min}$ to an isotherm of $300^{\circ} \mathrm{C}$, which was maintained for $0.52 \mathrm{~min}$. This amounted to a total chromatographic time of $5 \mathrm{~min}$. The MSD transfer line temperature was set at $280^{\circ} \mathrm{C}$ and that of the quadrupole and source at $150{ }^{\circ} \mathrm{C}$ and $230^{\circ} \mathrm{C}$, respectively. A solvent delay time of $0.9 \mathrm{~min}$ was set before the source was turned on. All mass spectra were recorded at $70 \mathrm{eV}$ (electron impact, positive mode) with an EM offset of $+200 \mathrm{~V}$.

Chromatograms were first recorded in full-scan mode $(50-550 \mathrm{~m} / \mathrm{z})$ to identify analytes and their respective retention times. Routine confirmation and quantitation was performed in the selected-ion monitoring (SIM) mode with respect to three significant ions for each compound and two for each IS. Positive confirmation utilizing three significant ions was in accordance with published recommendations [31]. The mass-to-charge ratios $(\mathrm{m} / \mathrm{z})$ of the analyte ions used for quantitation in SIM mode are indicated in Table 1. Eight SIM time-windows were set to monitor the aforementioned analytes, with a maximum of eight ions (10 ms dwell-time per ion)
Table 1

The mass-to-charge ratios $(\mathrm{m} / \mathrm{z})$ of the analyte ions used for the quantitation in SIM mode.

\begin{tabular}{llll}
\hline Analyte & $\begin{array}{l}\text { Qualifier ion 1 } \\
\text { (Relative } \\
\text { abundance \%) }\end{array}$ & $\begin{array}{l}\text { Qualifier ion 2 } \\
\text { (Relative } \\
\text { abundance \%) }\end{array}$ & $\begin{array}{l}\text { Quantifier ion } \\
\text { (Relative } \\
\text { abundance \%) }\end{array}$ \\
\hline $\begin{array}{l}\text { Amphetamine } \\
\text { Methamphetamine }\end{array}$ & $\begin{array}{c}91(42) \\
\text { Norephedrine }\end{array}$ & $118(79)$ & $190(100)$ \\
Ephedrine & $253(6)$ & $160(28)$ & $204(100)$ \\
Methcathinone & $160(20)$ & $280(14)$ & $190(100)$ \\
MDA & $105(95)$ & $294(4)$ & $204(100)$ \\
MDMA & $135(100)$ & $325(16)$ & $204(100)$ \\
MDEA & $160(32)$ & $339(17)$ & $162(45)$ \\
MBDB & $162(44)$ & $353(12)$ & $204(100)$ \\
{$\left[{ }^{2} \mathrm{H}_{11}\right]$ AMP } & $218(100)$ & $353(12)$ & $218(100)$ \\
{$\left[{ }^{2} \mathrm{H}_{9}\right]$ MET } & $128(74)$ & & $176(59)$ \\
{$\left[{ }^{2} \mathrm{H}_{3}\right]$ NE } & $163(28)$ & & $194(100)$ \\
{$\left[{ }^{2} \mathrm{H}_{3}\right]$ EPH } & $283(15)$ & & $193(100)$ \\
{$\left[{ }^{2} \mathrm{H}_{5}\right] \mathrm{MDA}$} & $297(5)$ & & $207(100)$ \\
{$\left[{ }^{2} \mathrm{H}_{5}\right] \mathrm{MDMA}$} & $330(16)$ & & $167(43)$ \\
{$\left[{ }^{2} \mathrm{H}_{6}\right]$ MDEA } & $344(14)$ & & $208(100)$ \\
\hline
\end{tabular}

monitored per window for collection of sufficient number of data-points that adequately defined chromatographic peaks.

\subsection{Sample preparation}

The method of Beck and Faull [32] was adapted and modified as follow. Solid $\mathrm{NaHCO}_{3}(150 \mathrm{mg})$ was added 'volumetrically' to urine aliquots $(950 \mu \mathrm{l})$ containing IS $(50 \mu \mathrm{l})$ and vortexed $(10 \mathrm{~s})$. Dichloromethane $(1500 \mu \mathrm{l})$ was added, followed by addition of PFPA $(50 \mu \mathrm{l})$. The acylation reaction started immediately after addition of PFPA, and samples were shaken $(2 \mathrm{~min})$ on a mechanical multi-shaker. Thereafter, samples were centrifuged $(2 \mathrm{~min}, 3500 \mathrm{rpm})$ to achieve adequate phase separation and the organic phase $( \pm 1000 \mu \mathrm{l})$ transferred into a clean GC vial. Care was taken not to aspirate and transfer any of the excess solid $\mathrm{NaHCO}_{3}$ along with the organic phase. The extract was gently dried under nitrogen ( $\pm 5 \mathrm{~min}$ ) and additional PFPA added $(50 \mu \mathrm{l})$ for derivatization $\left(10 \mathrm{~min}, 80^{\circ} \mathrm{C}\right)$ of $\beta$-hydroxy groups of the ephedra compounds. Excess PFPA was removed at room temperature under a stream of dry nitrogen ( $\pm 5 \mathrm{~min}$ ) and reconstituted with $\mathrm{CH}_{2} \mathrm{Cl}_{2}(60 \mu \mathrm{l})$ prior to GC-MS analysis.

\subsection{Linearity and selectivity}

Blank urine samples, obtained from ten healthy drug-free volunteers, were analyzed and compared to a standard $(200 \mathrm{ng} / \mathrm{mL})$ containing AMP, MET, MCA, CT, NE, NPE, EPH, PEP, PHM, FFA, MDA, MDMA, MDEA, MBDB and HMMA. The comparison was based on the presence of three characteristic ions (one quantifier ion, two qualifier ions) that eluted at the same retention time as the standards. CT, NPE, PEP, PHM, FFA and HMMA were included to assess the assay selectivity as far as adequate chromatographic resolution between closely related compounds and suspected interferences from authentic samples were concerned. In the absence of interfering peaks from the ten blank samples, the urine was pooled for further experiments.

Aliquots $(900 \mu \mathrm{L})$ from the urine pool were spiked with corresponding standard solutions $(50 \mu \mathrm{L}$ of each calibration standard obtained from solution A and B, respectively) along with the internal standard mixture $(50 \mu \mathrm{L})$ to obtain an eight point calibration of $5,25,50,100,200,500,1000$ and $5000 \mathrm{ng} / \mathrm{mL}$ with five replicates at each level. This was a wide-range linearity assessment, and from these results a routine calibration range could be determined. Criteria for acceptability of wide-ranging linearity were correlation coefficients $\left(r^{2}\right)$ should exceed or equal 0.99 and back-calculated values of standards should fall within $10 \%$ of respective theoretical values (20\% at lower limit of quantitation, LLQ). An un-weighted, leastsquares regression model was utilized to describe the peak area ratios of analyte versus the internal standards in the final linear range $5-500 \mathrm{ng} / \mathrm{mL}$

\subsection{Calibration curves and control samples}

An aliquot $(950 \mu \mathrm{L})$ from a urine pool was placed in a reaction vial $(7 \mathrm{~mL})$. Calibration standard solution $(50 \mu \mathrm{L})$ containing AMP, MET, MCA, NE, EPH, MDA, MDMA, MDEA and MBDB was added to the sample along with the internal standard mixture $(50 \mu \mathrm{L})$ to yield final calibration standards of $6.25,12.5,25,50,100$ and $200 \mathrm{ng} / \mathrm{mL}$ in urine. Each calibration contained a reagent-blank (no urine or IS), a matrix-blank (urine with no IS), and a zero-blank (urine with IS) to check for any possible background contributions to measured signals. Before analysis of an authentic specimen, the zero-blank was re-analysed to monitor for possible carryover from previous injected samples. Control samples were spiked in pooled urine 
(1 mL) from appropriate solutions to provide four QC levels: $6.25 \mathrm{ng} / \mathrm{mL}$ (LLQC), $50 \mathrm{ng} / \mathrm{mL}$ (LOW), $100 \mathrm{ng} / \mathrm{mL}$ (MED), and $200 \mathrm{ng} / \mathrm{mL}$ (HIGH).

\subsection{Accuracy and precision}

The performance of the method was evaluated according to international recommendations [33,34]. A daily six-point calibration curve along with three replicates of the four QC samples (LLQC, LOW, MED, and HIGH) described in the preceding text were analysed on 8 different days. Accuracy was determined as the percent bias of the mean of the calculated concentrations at the different levels with respect to their nominal concentrations. Precision was assessed by calculating relative standard deviation (\% RSD) for within-day (repeatability) and intermediate variation by one-way ANOVA. Criteria for acceptance were equal or less than 15\% RSD (20\% at LLQ) and within $15 \%$ of nominal concentration (20\% at LLQ) for precision and accuracy, respectively. Additional EQC (Liquichek ${ }^{\mathrm{TM}}$ Level $\mathrm{C} 1$ ) samples at the concentration values of MED control were also analysed over a period of six months. Precision and accuracy data for analytes that occur in both QC and EQC samples were compared.

\subsection{Stability}

The processed sample stability of the pentafluoroproprionyl (PFP)-derivatives was studied over a period of $24 \mathrm{~h}$ by injection of the same sample (MED QC) once every $2 \mathrm{~h}$. Absolute peak areas of each analyte versus injection time were plotted and instability indicated by a negative slope significantly different from zero $(p \leq 0.05)$ [34].

Stability studies in the present work were reduced to only freeze-thaw and longterm stability of MCA. Replicates ( $n=3$ each level) of spiked urine ( $50 \mathrm{ng} / \mathrm{mL}$ and $200 \mathrm{ng} / \mathrm{mL}$ ) before and after 3 freeze-thaw cycles were analyzed and the accuracy compared. The appearance of any of the ephedra components in the thawed samples (NE, NPE, EPH, PEP) was closely monitored. Long-term storage at $-20^{\circ} \mathrm{C}$ for MCA was assessed through repeat analysis of an authentic urine sample that was stored for 3 months in standard polypropylene specimen collection containers.

\subsection{Limits of quantitation and detection}

The lower limit of quantitation in SIM mode was determined to be the lowest calibrator $(6.25 \mathrm{ng} / \mathrm{mL})$ according to the following criteria. All three significant ions in the sample spectrum had to be within $20 \%$ of the mean ion ratios for calibrators at minimum $S / N=10$, while precision was within $20 \%$ RSD and accuracy within $20 \%$ of nominal concentration. The limit of detection (LOD) was determined by diluting the lowest calibrator, and criteria for acceptance were set as three significant ions present at minimum $S / N=3$. Peak height above baseline noise, as determined in the aforementioned analysis of 10 blank urine specimens, was used to calculate $S / N$.

\section{Results}

\subsection{GC-MS analysis}

The PFP-derivatives of the studied compounds produced mass spectra with structure-specific ions in relative high abundances. The fragmentation patterns of the analytes of interest were similar, as could be expected from the structural similarities shared between amphetamine and related analogs. A typical fragmentation, common to all studied analytes, occurred on the side chain between the $\alpha$ - and $\beta$-carbon (see Fig. 1 ) to yield two main positively charged fragments used for identification and quantitation. Abundant molecular ions were only attained for the methylenedioxy derivatives MDA, MDMA, MDEA and MBDB. The CT mass spectrum indicated a significant ion at $m / z 105$ from the $\left[\mathrm{C}_{7} \mathrm{H}_{5} \mathrm{O}\right]^{+}$fragment, and a much smaller signal at $\mathrm{m} / \mathrm{z} 190$ $\left[\mathrm{C}_{5} \mathrm{H}_{5} \mathrm{NOF}_{5}\right]^{+}$. This is in accordance with findings on the heptafluorobutyric- (HFB) derivative of CT by Paul and Cole [10]. MCA mass spectrum also proved to have $m / z 105$ as base peak, but with $m / z 204\left[\mathrm{C}_{6} \mathrm{H}_{7} \mathrm{NOF}_{5}\right]^{+}$in a near one-to-one ratio. Quantitation was supported through the use of the more structure-specific ion. The use of common ions (Table 1) imposed even more stringent requirements on chromatographic resolution.

An extract of urine spiked with relevant analytes and potentially interfering compounds $(200 \mathrm{ng} / \mathrm{mL})$ recorded in SIM

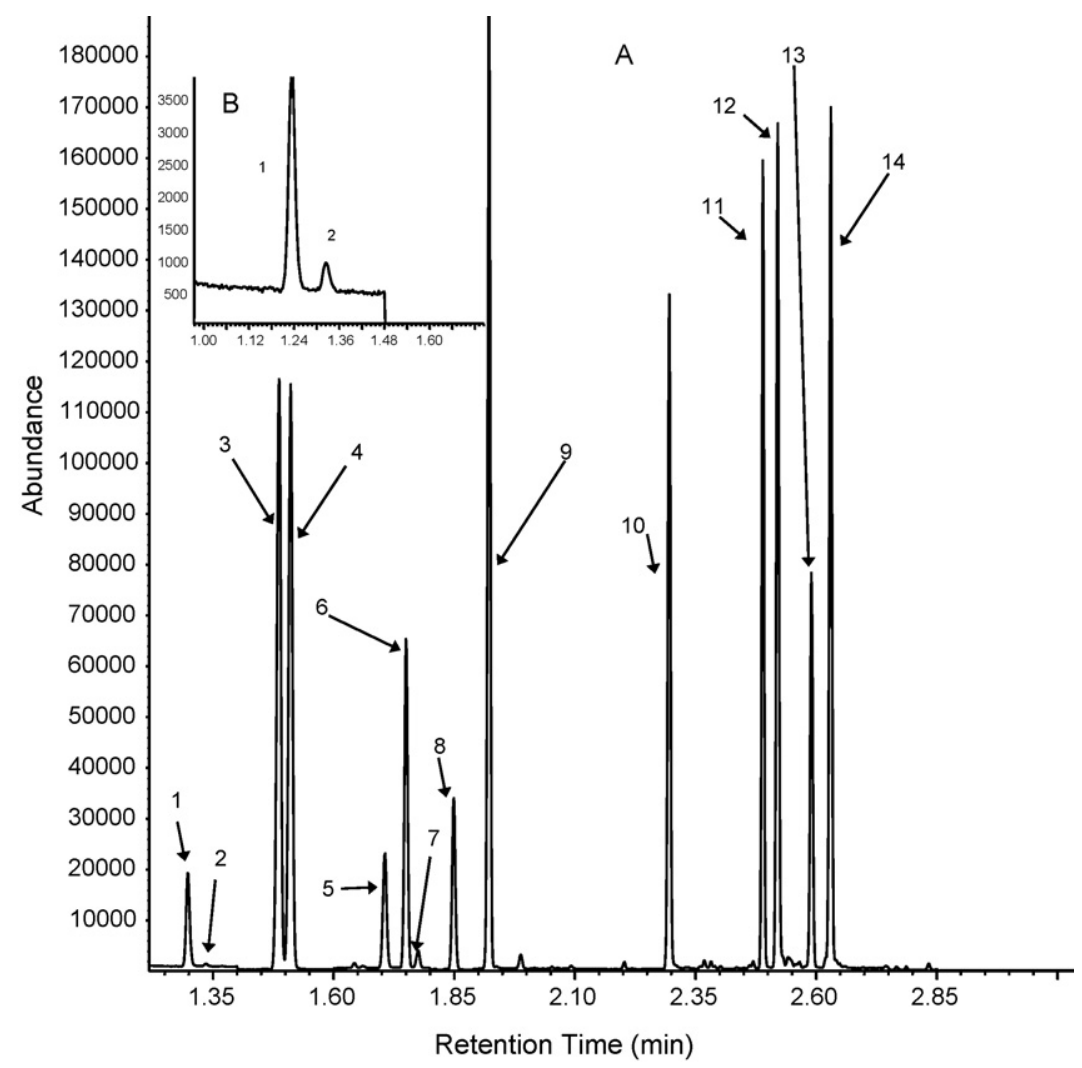

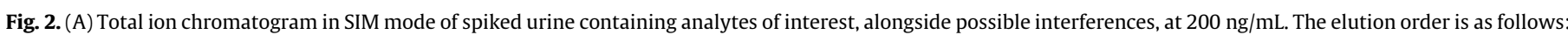

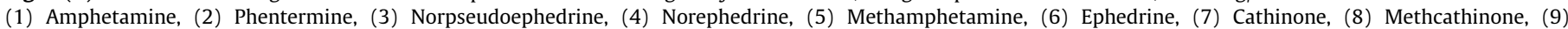

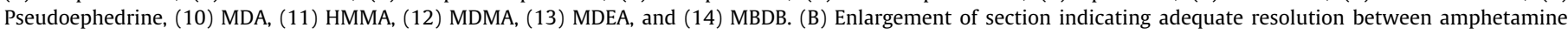
and phentermine for the shared ion $91 \mathrm{~m} / \mathrm{z}$. 
mode is shown in Fig. 2. Only common ions between analytes of interest and interferences, as determined in full scan mode, were included in SIM mode. None of the suspected interferences coeluted with the analytes of interest at concentrations of $200 \mathrm{ng} / \mathrm{mL}$ and $2000 \mathrm{ng} / \mathrm{mL}$. Fenfluramine is not indicated on the chromatogram due to the change of monitored SIM window at its retention time, but elutes with baseline separation between CT (peak 7) and MCA (peak 8).

Analysis of the zero-blank samples indicated no contribution from deuterium substituted internal standards to selected quantitation ions for relevant compounds. The total absence of chromatographic peaks containing the aforementioned quantitation ions indicated that no carry-over from samples containing high concentrations of analytes to the following samples in a sequence occurred. No contribution was observed during validation experiments when LLQ samples were continually injected after HIGH QC specimens.

Resolution between diastereomers such as NE and NPE, EPH and PEP, as well as structurally close related compounds such as MDEA and MBDB were achieved in less than 3 min using the selected chromatographic conditions. A total instrumental cycle-time of 6 min per sample was obtained, which compares favourably with current rapid chromatographic methodologies for both GC-MS and LC-MS/MS [16,21]. The total sample preparation time for a batch of 20 specimens, performed by a single analyst, was approximately $45 \mathrm{~min}$. Considering the instrument cycle-time of 6 min per sample, the total analysis time was therefore less than $3 \mathrm{~h}$ for such a batch. A single analyst could thus comfortably start the instrumental analysis and continue serially preparing new specimen batches, allowing up to 100 specimens to be analysed in approximately $10 \mathrm{~h}$.

Specific ions for CT, NPE and PEP were monitored in the final GC-MS SIM method and their appearance in authentic urine specimens qualitatively assessed.

\subsection{Validation}

A minimum of 5 data points were collected over the peak area. This has been shown to be sufficient for accurate quantitation with a conventional quadrupole mass spectrometer in fast GC-MS analysis [28,30]. Variation that results from integration of inadequately defined signals would be reflected as decreased precision (increased \% RSD), especially at LLQ concentrations. Variation arising from sample preparation steps was, however, likely to play a more significant role. The established criteria were satisfied for all the relevant compounds across the calibration range. Table 2 indicates validation data for precision, accuracy and LOD for the current GC-MS assay. Precision and accuracy of internal quality control specimens were compared with external quality control specimens $(n=12)$ that have been analyzed over a

Table 2

Validation data for GC-MS assay.

\begin{tabular}{|c|c|c|c|c|c|}
\hline Analyte (IS) & $\begin{array}{l}\text { Control level } \\
(\mathrm{ng} / \mathrm{mL})\end{array}$ & $\begin{array}{l}\text { Accuracy } \\
\text { (\% Bias) }\end{array}$ & $\begin{array}{l}\text { Repeatability } \\
\text { (\% RSD) }\end{array}$ & $\begin{array}{l}\text { Intermediate } \\
\text { precision (\% RSD) }\end{array}$ & LOD $(\mathrm{ng} / \mathrm{mL})$ \\
\hline Amphetamine ([ $\left.{ }^{2} \mathrm{H}_{11}\right]$ AMP $)$ & $\begin{array}{l}\text { LLQC (6.25) } \\
\text { LOW }(50) \\
\text { MED }(100) \\
\text { HIGH }(200)\end{array}$ & $\begin{array}{r}-8.1 \\
3.5 \\
1.8 \\
3.1\end{array}$ & $\begin{array}{l}6.2 \\
5.7 \\
4.1 \\
5.3\end{array}$ & $\begin{array}{l}8.0 \\
5.9 \\
7.3 \\
7.1 \\
\end{array}$ & 6.25 \\
\hline Methamphetamine $\left(\left[{ }^{2} \mathrm{H}_{9}\right] \mathrm{MET}\right)$ & $\begin{array}{l}\text { LLQC (6.25) } \\
\text { LOW }(50) \\
\text { MED }(100) \\
\text { HIGH }(200)\end{array}$ & $\begin{array}{r}-4.1 \\
3.4 \\
0.9 \\
1.1\end{array}$ & $\begin{array}{l}5.5 \\
3.0 \\
3.5 \\
2.5\end{array}$ & $\begin{array}{l}9.6 \\
4.3 \\
4.8 \\
8.2 \\
8.2\end{array}$ & 3.1 \\
\hline Norephedrine $\left(\left[{ }^{2} \mathrm{H}_{3}\right] \mathrm{NE}\right)$ & $\begin{array}{l}\text { LLQC (6.25) } \\
\text { LOW (50) } \\
\text { MED (100) } \\
\text { HIGH (200) }\end{array}$ & $\begin{array}{r}-9.5 \\
5.1 \\
2.9 \\
1.2\end{array}$ & $\begin{array}{r}10.7 \\
4.8 \\
3.2 \\
5.2\end{array}$ & $\begin{array}{r}12.3 \\
5.4 \\
5.0 \\
5.8\end{array}$ & 6.25 \\
\hline Ephedrine $\left(\left[{ }^{2} \mathrm{H}_{3}\right]\right.$ EPH $)$ & $\begin{array}{l}\text { LLQC (6.25) } \\
\text { LOW (50) } \\
\text { MED (100) } \\
\text { HIGH (200) }\end{array}$ & $\begin{array}{l}7.3 \\
4.1 \\
2.3 \\
2.5\end{array}$ & $\begin{array}{l}9.3 \\
4.1 \\
2.3 \\
3.5\end{array}$ & $\begin{array}{r}10.5 \\
5.3 \\
5.2 \\
7.9\end{array}$ & 6.25 \\
\hline Methcathinone $\left(\left[{ }^{2} \mathrm{H}_{3}\right] \mathrm{EPH}\right)$ & $\begin{array}{l}\text { LLQC (6.25) } \\
\text { LOW }(50) \\
\text { MED }(100) \\
\text { HIGH (200) }\end{array}$ & $\begin{array}{l}-1.3 \\
-6.0 \\
-1.7 \\
-4.6\end{array}$ & $\begin{array}{r}11.7 \\
9.7 \\
6.4 \\
6.7\end{array}$ & $\begin{array}{l}12.2 \\
12.0 \\
13.8 \\
12.6\end{array}$ & 3.1 \\
\hline $\operatorname{MDA}\left(\left[{ }^{2} \mathrm{H}_{5}\right] \mathrm{MDA}\right)$ & $\begin{array}{l}\text { LLQC (6.25) } \\
\text { LOW }(50) \\
\text { MED }(100) \\
\text { HIGH }(200)\end{array}$ & $\begin{array}{r}-7.9 \\
4.6 \\
2.5 \\
0.4\end{array}$ & $\begin{array}{l}6.5 \\
4.6 \\
2.6 \\
3.0 \\
\end{array}$ & $\begin{array}{r}13.8 \\
6.8 \\
8.0 \\
6.7\end{array}$ & 1.5 \\
\hline MDMA $\left(\left[{ }^{2} \mathrm{H}_{5}\right]\right.$ MDMA $)$ & $\begin{array}{l}\text { LLQC (6.25) } \\
\text { LOW (50) } \\
\text { MED (100) } \\
\text { HIGH (200) }\end{array}$ & $\begin{array}{r}0.8 \\
3.2 \\
1.4 \\
-1.5\end{array}$ & $\begin{array}{l}5.9 \\
2.7 \\
2.4 \\
1.8\end{array}$ & $\begin{array}{l}6.3 \\
6.0 \\
4.8 \\
6.4\end{array}$ & 1.5 \\
\hline $\operatorname{MDEA}\left(\left[{ }^{2} \mathrm{H}_{6}\right] \mathrm{MDEA}\right)$ & $\begin{array}{l}\text { LLQC (6.25) } \\
\text { LOW }(50) \\
\text { MED }(100) \\
\text { HIGH }(200)\end{array}$ & $\begin{array}{r}-8.7 \\
3.1 \\
1.3 \\
-2.2\end{array}$ & $\begin{array}{l}6.1 \\
4.3 \\
2.8 \\
2.9\end{array}$ & $\begin{array}{r}10.8 \\
4.6 \\
8.5 \\
9.3\end{array}$ & 1.5 \\
\hline MBDB $\left(\left[{ }^{2} \mathrm{H}_{5}\right] \mathrm{MDMA}\right)$ & $\begin{array}{l}\text { LLQC }(6.25) \\
\text { LOW }(50) \\
\text { MED }(100) \\
\text { HIGH }(200)\end{array}$ & $\begin{array}{l}-1.7 \\
-2.3 \\
-0.2 \\
-1.6\end{array}$ & $\begin{array}{l}6.6 \\
4.4 \\
3.3 \\
6.5\end{array}$ & $\begin{array}{l}7.0 \\
7.3 \\
8.1 \\
8.9\end{array}$ & 1.5 \\
\hline
\end{tabular}


Table 3

Accuracy and precision comparison of internal quality control (QC) and external quality control (EQC) samples.

\begin{tabular}{lccllc}
\hline Analyte & \multicolumn{2}{l}{$\begin{array}{l}\text { Internal quality control } \\
\text { (MED, 100 ng/mL) }\end{array}$} & & \multicolumn{2}{l}{$\begin{array}{l}\text { External quality control } \\
\text { (Liquicheck C1, 100 ng/mL) }\end{array}$} \\
\cline { 2 - 3 } \cline { 6 - 7 } & Accuracy (\%) & RSD (\%) & & Accuracy (\%) & RSD (\%) \\
\cline { 6 - 7 } & 99 & 7.2 & & 89 & 5.8 \\
Amphetamine & 99 & 6.8 & & 90 & 5.7 \\
MDA & 101 & 5.9 & & 86 & 3.9 \\
MDMA & 98 & 6.2 & & 91 & 3.2 \\
MDEA & 101 & 7.1 & & 92 & 4.1 \\
\hline
\end{tabular}

period of 6 months. Not all analytes of interest were available in the EQC specimens. Results are shown in Table 3.

The limits of detection for AMP, NE and EPH were equal to the lower limit of quantitation as only two significant ions were present when diluted below a concentration of $6.25 \mathrm{ng} / \mathrm{mL}$. The LOD for the different analytes compared well to those published elsewhere [9].

The correlation coefficients for the calibration curves were in the range $0.993-0.999$ for all the analytes. Precision and accuracy were within to the aforementioned criteria.

The PFP-derivatives were sufficiently stable over a period of $24 \mathrm{~h}$ with no evidence of degradation observed. Comprehensive stability studies by Jiménez et al. [12] as well as published work by other authors $[22,35,36]$ have indicated the viable stability of amphetamine and related derivatives under various freeze-thaw and storage conditions. Freeze/thaw stability for MCA was also positively confirmed in agreement with reports in literature [22]. Re-analysis of an authentic urine specimen positive for MCA indicated that only concentrations for NE and EPH were within acceptable limits [34], whereas MCA was almost completely missing. Positive MCA urine specimens stored at $4{ }^{\circ} \mathrm{C}$ are reported as unstable [10]. Long-term stability data from this work suggests that storage at $-20^{\circ} \mathrm{C}$ for longer than two months is also not advised.

\subsection{Routine confirmation}

A typical chromatogram for a MCA positive urine specimen is presented in Fig. 3. High concentrations of EPH were observed with lower concentrations of NE and PEP present. NPE was excreted at much lower concentrations. These observations were in agreement with published findings $[10,11,40]$, however, no inferences with regards to metabolism can be made as no information about the precise composition of the ingested substance or the timeframe could be obtained. The quantified concentrations in this sample were as follow: $157463 \mathrm{ng} / \mathrm{mLEPH}$, $6752 \mathrm{ng} / \mathrm{mL} \mathrm{MCA}$, and $783 \mathrm{ng} / \mathrm{mL}$ NE.

A somewhat atypical chromatogram is presented in Fig. 4, as the concentration of PEP is higher than EPH. The most likely explanation for this is ingestion of a PEP contaminated preparation. This sample was also positive for MDMA and MDA, which had been indicated in a presumptive positive immunoassay screen. The quantified concentrations were as follow: $36056 \mathrm{ng} / \mathrm{mL}$ EPH, $22582 \mathrm{ng} / \mathrm{mL}$ MCA, $2080 \mathrm{ng} / \mathrm{mL}$ NE, $250 \mathrm{ng} / \mathrm{mL}$ MDMA, and $48 \mathrm{ng} / \mathrm{mL}$ MDA.

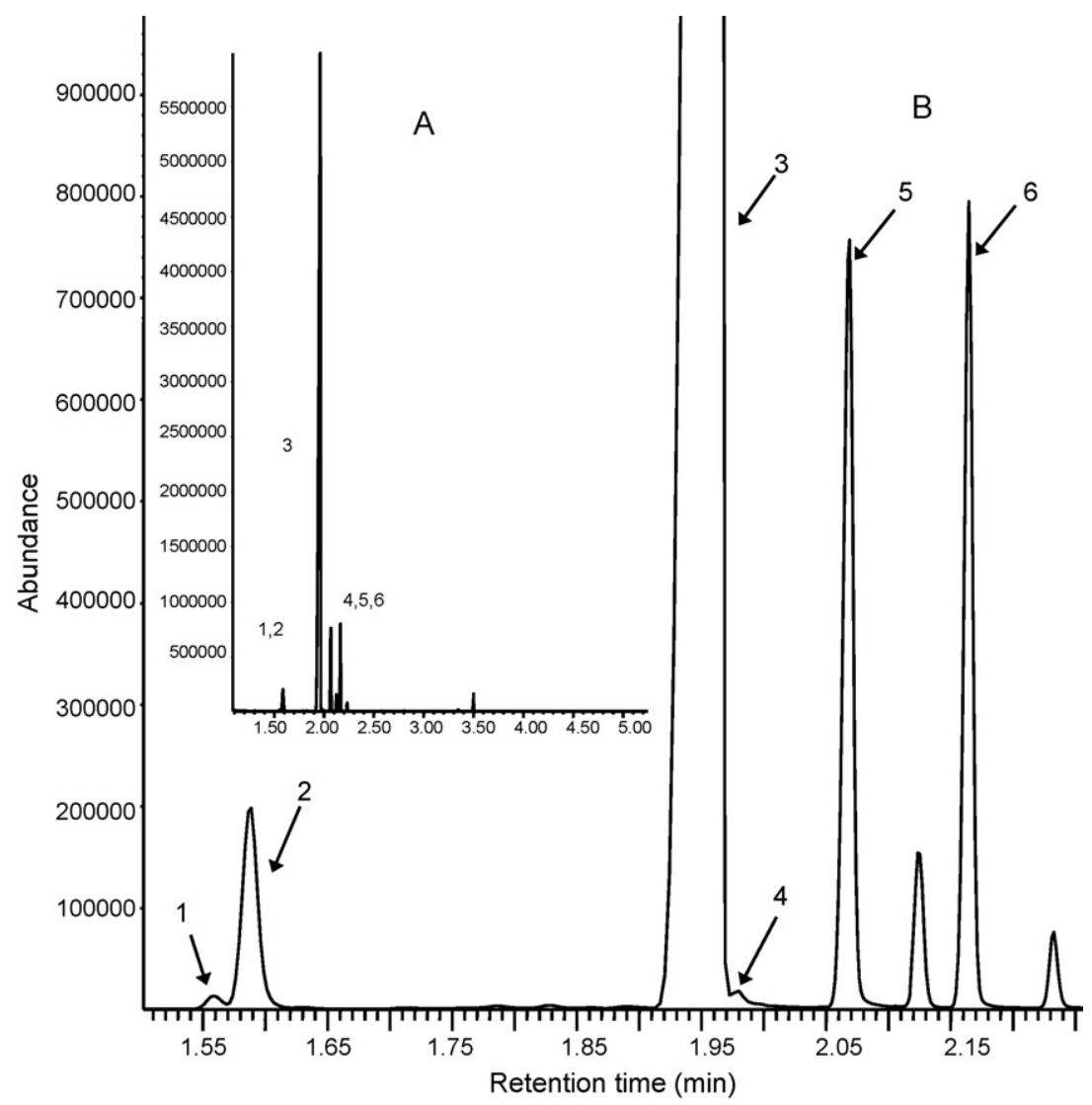

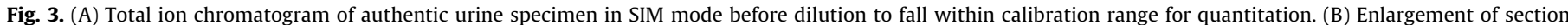

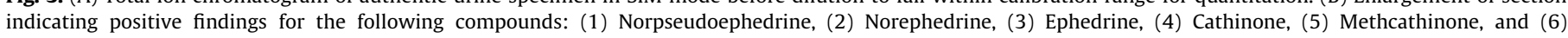
Pseudoephedrine. 


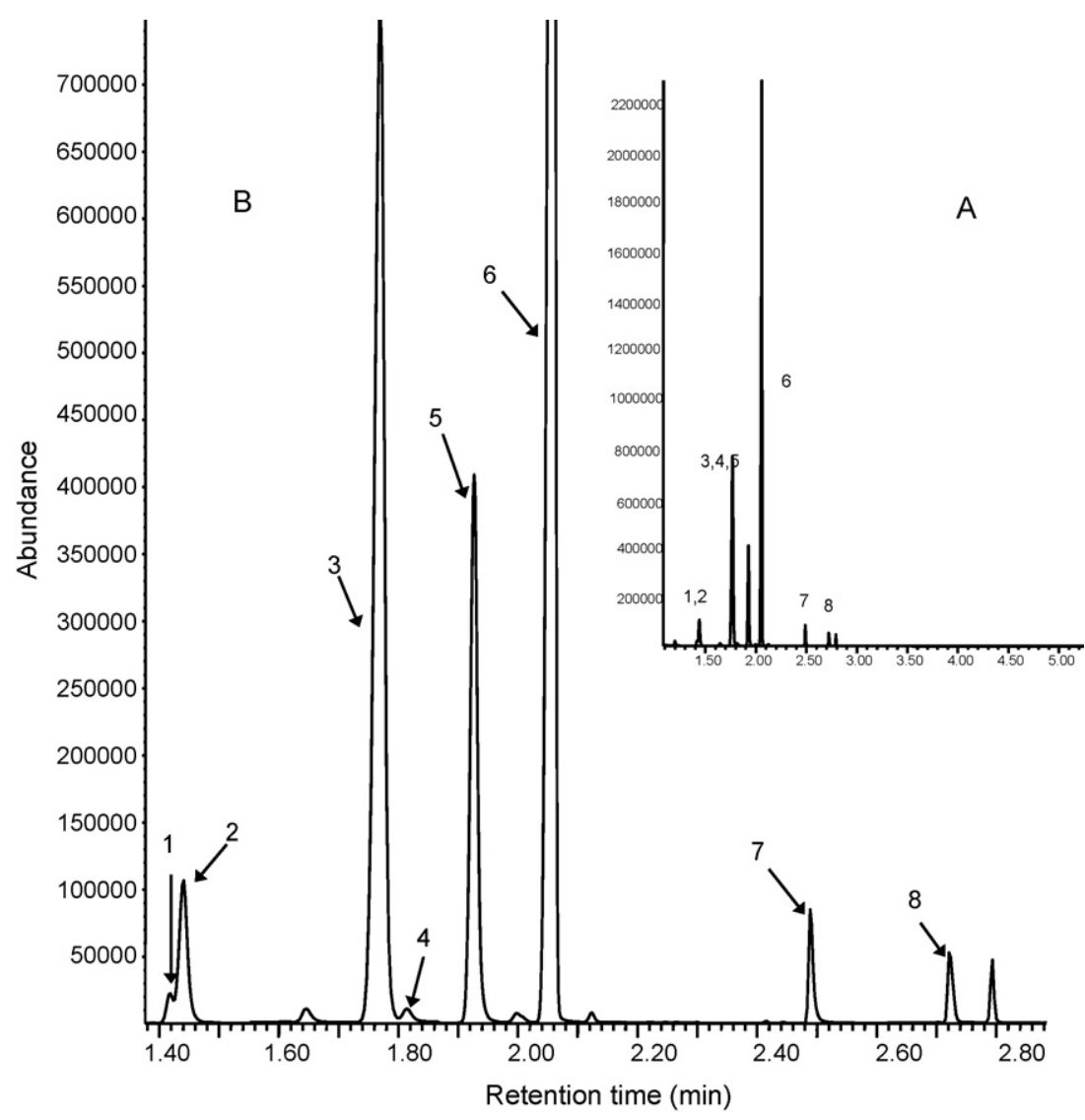

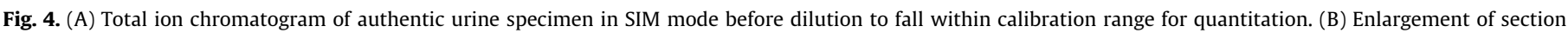

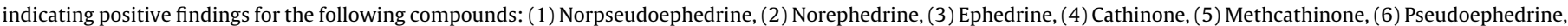
(7) MDA, and (8) MDMA.

\section{Discussion and conclusion}

Solid $\mathrm{NaHCO}_{3}$ was weighed off initially (150 mg); however, a 'volumetric' quantity also served the purpose $(150 \pm 5 \mathrm{mg})$. The volumetric addition eliminated the time to weigh out the correct amount for each sample, thereby reducing sample preparation time. The addition of $\mathrm{NaHCO}_{3}$ was a crucial step in the reaction as low derivatization efficiency was obtained when not present in excess. Acylation of primary and secondary amines as well as phenolic hydroxyl groups was achieved during the initial extractive-acylation, in agreement with Beck and Faull [32]. Derivatization in situ was advantageous as the PFP-derivatives were less subject to associated free-base amphetamine volatility and subsequent analyte loss in sample concentration procedures with nitrogen gas. Prolonged drying steps ( $>25 \mathrm{~min}$ ) resulted in decreased signal strength for AM, MET and MCA. Alcoholic functional groups such as the $\beta$-hydroxy groups of NE, NPE, EPH and PEP remained underivatized after the initial acylation reaction. No mixed derivatives of mono- (mono- $N$-PFP) and diacylated (bis- $N, O$-PFP) compounds in appreciable yield were found as reported in the extractive-derivatization technique of Kankaanpää et al. [21]. Formation of the diacylated derivatives of NE, NPE, EPH and PEP was preferred, as better chromatographic resolution and separation speed was achieved. Quantitation of EPH and NE as potential metabolites of MCA was required, and the additional derivatization step with PFPA was introduced. It was also found that less column maintenance along with prolonged column-lifetime was gained when an extra derivatization step was introduced.

A routine calibration range with low concentrations compared to international recommendations for confirmatory cut-offs [37] of amphetamine and related derivatives was used in the present method. The decision for this was based largely on the reported concentrations for MCA [10] along with the lack of information regarding the detection time window for MCA in positive urine specimens. Analysis of urine specimens in certain cases resulted in certain analyte concentrations to be within the calibration range while others were present at much higher concentrations. In such events, the analytes that were within the calibration range were immediately quantified and the urine specimens were appropriately diluted with deionized water, re-analysed and the previous higher-concentration analytes quantified.

Synthesis of MCA can be performed by relatively simple means through oxidation of EPH or PEP with a strong oxidizing agent such as potassium permanganate [38]. Illicit substances with MCA as the proposed major active ingredient can therefore be expected to contain EPH and/or PEP in appreciable amounts due to incomplete synthesis or as diluents in the so-called 'cutting' process. The presence of EPH and PEP in the urine of MCA abusers can also be expected as a result of metabolism [39]. Detection of CT and MCA by analysis of 4-carbethoxyhexafluorobutyryl chloride (4-CB) derivatives with GC-MS has been performed [10]. The presence of high concentrations of EPH and PEP, as may be expected for MCA users due to ingestion of precursor/contaminant EPH and PEP alongside their metabolic formation, presents a particular difficulty with this method. Detection of MET as an artifact of EPH and PEP resulting from derivatization with a.o. 4-CB, PFPA and HFBA have been reported [40]. Degradation of EPH and PEP by addition of sodium periodate prior to extraction has been recommended [41] and is an acceptable option for exclusive forensic confirmation of AMP and MET. Simultaneous detection of MCA alongside AMP and MET is however excluded, as the proposed reaction also destroys 
MCA [10] and is therefore not applicable in a multi-analyte confirmation procedure that includes MCA. Two separate sample preparations must be performed in the case of a positive screen for both MCA and MET, one with periodate treatment (AMP, MET) and one without (CT, MCA). Urine spiked with $2000 \mathrm{ng} / \mathrm{mL}$ EPH and PEP did not indicate the presence of MET following the current prescribed procedure. Authentic urine specimens with quantified concentrations of up to $100000 \mathrm{ng} / \mathrm{mL}$ of EPH and $30000 \mathrm{ng} / \mathrm{mL}$ of PEP also did not indicate the presence MET, before and after appropriate dilutions down to calibration range. It is our conclusion that the current GC-MS assay does not suffer from MET artifact formation in the presence of high concentrations of EPH and PEP. Simultaneous quantitation of MCA, MET, AMP, EPH and NE is therefore possible while qualitative data for CT, PEP and NPE is retained.

A previously unreported qualitative observation in certain MCA positive authentic urine samples is the appearance of CT (Figs. 3 and 4). The major metabolic pathway for MCA metabolism has been indicated to occur through stereoselective reduction of the ketone group to form EPH and PEP, which is further metabolised to NE and NPE, respectively, by $N$-dealkylation [39]. The reported concentrations for MCA in this study are much higher than those previously indicated [10]. Formation of CT may thus be a very minor pathway where MCA follows a $\mathrm{N}$ demethylation route after intake of large dosages, and may possibly be detected in the very early phase of excretion. The possibility of ingestion of a CT contaminated preparative can unfortunately not be excluded, and the appearance of the analyte may be artifactual in this sense. The appearance of higher concentrations of MCA and EPH in the specimens excludes the possibility of pure $\mathrm{CT}$ ingestion, however.

Amphetamine-class confirmatory analysis on 119 urine specimens, forwarded by referring clinicians who requested direct amphetamine class confirmations irrespective of a positive or negative immunoassay screen, resulted in a total of 21 positive specimens (18\%) of which 17 of the positive specimens (81\%) confirmed for MCA use. Only 2 of these positive MCA samples were presumptive positives in on-site immunoassay screening kits, likely due to the synergistic cross-reactive effect of very high concentrations of EPH, PEP, NE and NPE. The need for accurate screening techniques for MCA is however indicated.

Many specimens only tested positive for a combination of EPH, PEP, NE and NPE. This may well be due to sampling in the late excretion phase after MCA usage, but the availability of these compounds as common over-the-counter medicaments denotes that such detection cannot be considered as characteristic for MCA abuse. However, with no valid explanation for their appearance in a urine specimen, further investigation using alternative matrices such as hair may be prudent to establish possible historic abuse. Care in reporting true positive MCA specimens is also required, as alkylated homologs such as the anorexant dimethylpropion ( $N, N$-dimethylcathinone) is known to have MCA as metabolite [39].

In a clinical laboratory setting various analysts usually perform expedient sample preparation and data interpretation, but reporting of results may be delayed due to slow data acquisition from lengthy instrumental analysis. Instrument availability in such events is the most limiting time factor [29]. Literature reports, with similar fast sample preparation times for GC-MS multi-analyte analysis of amphetamines [21] as the current assay, seem to be hindered by lengthy analytical runs (up to $15 \mathrm{~min}$ ). The most rapid chromatographic techniques with similar instrument cycle-times are LC-MS/MS methodologies [22,23], which in this instance have lengthier sample preparation steps than the current assay. The complimentary approach of fast GC-MS alongside relatively rapid sample preparation fulfilled the short turnaround time requirements of a routine clinical laboratory that deal in forensic urine confirmations for drugs of abuse.

\section{Conflict of interest}

No conflict of interest with regards to the present study exists.

\section{Acknowledgements}

The authors express their gratitude toward the Department of Chemistry, University of Pretoria, South Africa for supporting and funding this research. Special thanks to Dr. P. Bekker for his assistance with statistical data analysis and Mr. B. Marais for technical advice.

\section{References}

[1] A. Plüddeman, C. Parry, A. Bhana, Alcohol and Drug Abuse Trends: January 2007June 2007, South African Community Epidemiology Network on Drug Use (SACENDU), 2007 (Accessed December 2007) http://www.sahealthinfo.org/ admodule/sacendu.htm.

[2] B.K. Logan, Amphetamines: an update on forensic issues, J. Anal. Toxicol. 25 (2001) 400-404.

[3] A.M. Bar, W.J. Panenka, W. MacEwan, A.E. Thornton, D.J. Lang, W.E. Honer, T. Lecomte, The need for speed: an update on methamphetamine addiction, J. Psychiatry Neurosci. 31 (2006) 301-313.

[4] R.A. Glenon, M. Yousef, N. Naiman, P. Kalix, Methcathinone: a new potent amphetamine-like agent, Pharmacol. Biochem. Behav. 26 (1987) 547-551.

[5] M.P. Gygi, J.W. Gibb, G.R. Hanson, Methcathinone: an initial study of its effects on monoaminergic systems, J. Pharmacol Exp. Ther. 276 (1996) 1066-1072.

[6] R.A. Glenon, R. Young, B.R. Martin, T.A. Dal-Cason, Methcathinone ("Cat"): an enantiomeric potency comparison, Pharmacol. Biochem. Behav. 50(1995)601-606.

[7] O.H. Drummer, Pharmacokinetics and metabolism, in: A.C. Moffat, J.V. Jackson, M.S. Moss, B. Widdop (Eds.), 3rd ed., Clarke's Analysis of Drugs and Poisons, vol. 2, Pharmaceutical Press, London, 2004, pp. 172-188.

[8] T. Kraemer, H.H. Maurer, Toxicokinetics of amphetamines: metabolism and toxicokinetic data of designer drugs, amphetamine, methamphetamine, and their N-alkyl derivatives, Ther. Drug. Monit. 24 (2002) 277-289.

[9] T. Kraemer, H.H. Maurer, Determination of amphetamine, methamphetamine and amphetamine-derived designer drugs or medicaments in blood and urine, J. Chromatogr. B 713 (1998) 163-187.

[10] B.D. Paul, K.A. Cole, Cathinone (Khat) and methcathinone (CAT) in urine specimens: a gas chromatographic-mass spectrometric detection procedure, J. Anal. Toxicol. 25 (2001) 525-530.

[11] S.W. Toennes, G.F. Kauert, Excretion and detection of cathinone, cathine, and phenylpropanolamine in urine after kath chewing, Clin. Chem. 48 (2002) 1715-1719.

[12] C. Jiménez, R. De la Torre, M. Ventura, J. Segura, R. Ventura, Stability studies of amphetamine and ephedrine derivatives in urine, J. Chromatogr. B 843 (2006) 84-93.

[13] C. Soriano, J. Munoz-Guerra, D. Carreras, C. Rodriguez, A.F. Rodriguez, R. Cortes, Automated analysis of drugs in urine, J. Chromatogr. B 687 (1996) 183-187.

[14] D. Talwar, I.D. Watson, M.J. Stewart, Routine analysis of amphetamine class drugs as their naphthaquinone derivatives in human urine by high-performance liquid chromatography, J. Chromatogr. B 735 (1999) 229-241.

[15] Y. He, A. Vargas, Y.J. Kang, Headspace liquid-phase microextraction of methamphetamine and amphetamine in urine by an aqueous drop, Anal. Chim. Acta 589 (2007) 225-230.

[16] K.L. Klette, M.H. Jamerson, C.L. Morris-Kukoski, A.R. Kettle, J.J. Snyder, Rapid simultaneous determination of amphetamine, methamphetamine, 3,4-methylenedioxyamphetamine, 3,4-methylenedioxymethamphetamine, and 3,4-methylenedioxyethylamphetamine in urine by fast gas chromatography-mass spectrometry, J. Anal. Toxicol. 29 (2005) 669-674.

[17] F.T. Peters, F. Schaefer, R.F. Staack, T. Kraemer, H.H. Maurer, Screening for and validated quantification of amphetamines and amphetamine- and piperazinederived designer drugs in human blood plasma by gas chromatography-mass spectrometry, J. Mass Spectrom. 38 (2003) 659-676.

[18] D.L. Lin, H.C. Lui, R.M. Yin, D.T. Chen, S.J. Soong, R.H. Lui, Effectiveness of multiple internal standards: deuterated analogues of methylenedioxymethamphetamine, methylenedioxyamphetamine, methamphetamine and amphetamine, J. Anal. Toxicol. 28 (2004) 650-654.

[19] T. Kumazawa, C. Hasegawa, X.P. Lee, K. Hara, H. Seno, O. Suzuki, K. Sato Simultaneous determination of methamphetamine and amphetamine in human urine using pipette tip solid-phase extraction and gas chromatography-mass spectrometry, J. Pharm. Biomed. Anal. 44 (2007) 602-607.

[20] K. Kudo, T. Ishida, K. Hara, S. Kashimura, A. Tsuji, N. Ikeda, Simultaneous determination of 13 amphetamine related drugs in human whole blood using an enhanced polymer column and gas chromatography-mass spectrometry, J. Chromatogr. B 855 (2007) 115-120. 
G Model

FSI-5552; No of Pages 9

A.A.S. Marais, J.B. Laurens/Forensic Science International xxx (2008) $x x x-x x x$

9

[21] A. Kankaanpää, T. Gunnar, K. Ariniemi, P. Lillsunde, S. Mykkänen, T. Seppälä, Single-step procedure for gas chromatography-mass spectrometry screening and quantitative determination of amphetamine-type stimulants and related drugs in blood, serum, oral fluid and urine samples, J. Chromatogr. B 810 (2004) 57-68.

[22] J. Beyer, F.T. Peters, T. Kraemer, H.H. Maurer, Detection and validated quantification of nine herbal phenalkylamines and methcathinone in human blood plasma by LC-MS/MS with electrospray ionisation, J. Mass Spectrom. 42 (2007) 150-160.

[23] M. Concheiro, S.M. dos Santos Sadler Simões, O. Quintela, A. de Castro, M.J. Rodrigues Dias, A. Cruz, M.L. Rivadulla, Fast LC-MS/MS method for the determination of amphetamine, methamphetamine, MDA, MDMA, MDEA, MBDB and PMA in urine, Forensic Sci. Int. 171 (2007) 44-51.

[24] A.G. Verstaete, F. van der Heyden, Comparison of the sensitivity and specificity of six immunoassays for the detection of amphetamines in urine, J. Anal. Toxicol. 29 (2005) 359-364.

[25] H.H. Maurer, Systematic toxicological analysis of drugs and their metabolites by gas chromatography-mass spectrometry, J. Chromatogr. B 580 (1992) 3-41.

[26] H. Fujii, K. Hara, S. Kashimura, M. Kageura, M. Kashiwagi, A. Miyoshi, S. Ikeda, Rapid GC-MS analysis of methamphetamine and its metabolites in urine application of short narrow-bore capillary column to GC-MS, J. Chromatogr. B 842 (2006) 116-120.

[27] S.G. McKinley, J.J. Snyder, E. Welsh, C.M. Kazarian, M.H. Jamerson, K.L. Klette, Rapid quantification of urinary oxycodone and oxymorphone using fast gas chromatography-mass spectrometry, J. Anal. Toxicol. 31 (2007) 434-441.

[28] J. Dallüge, R.J.J. Vreuls, D.J. van Iperen, M. van Rijn, U.A.Th. Brinkman, Resistively heated gas chromatography coupled to quadropole mass spectrometry, J. Sep. Sci. 25 (2002) 608-614.

[29] K. Maštovská adn, S.J. Lehotay, Practical approaches to fast gas chromatographymass spectrometry, J. Chromatogr. A 1000 (2003) 153-180.

[30] M. Kirchner, E. Matisová, S. Hrouzková, J. de Zeeuw, Possibilities and limitations of quadrupole mass spectrometric detector in fast gas chromatography, J. Chromatogr. A 1090 (2005) 126-132.
[31] L. Rivier, Criteria for identification of compounds by liquid chromatography-mass spectrometry and liquid chromatography-multiple mass spectrometry in forensic toxicology and doping analysis, Anal. Chim. Acta 492 (2003) 69-82.

[32] O. Beck, K.F. Faull, Extractive acylation and mass spectrometric assay of 3methoxytyramine, normetanephrine and metanephrine in cerebrospinal fluid, Anal. Biochem. 149 (1985) 492-500.

[33] V.P. Shah, K.K. Mida, J.W.A. Findlay, H.M. Hill, J.D. Hulse, J.J. McGilveray, G. McKay, K.J. Miller, R.N. Patnaik, M.L. Powell, A. Tonnelli, C.T. Viswanattan, A. Jacobi, Bioanalytical method validation-a revisit with a decade of progress, Pharm. Res. 17 (2002) 1551-1557.

[34] F.T. Peters, O.H. Drummer, F. Musshoff, Validation of new methods, Forensic Sci. Int. 165 (2007) 216-224.

[35] R. Hughes, A. Hughes, B. Levine, M.L. Smith, Stability of phencyclidine and amphetamines in urine specimens, Clin. Chem. 37 (1991) 2141-2142.

[36] K.M. Clauwaert, J.F. van Bocxlaer, A.P. De Leenheer, Stability studies of the designer drugs "MDA, MDMA and MDEA" in water, serum, whole blood, and urine under various storage temperatures, Forensic Sci. Int. 124 (2001) 36-42.

[37] Substance abuse and mental health services administration (SAMHSA) (2002). http://www.samhsa.gov (Accessed May 2007).

[38] J. Deruiter, A. Valaer, C.R. Clark, F.T. Noggle, Methcathinone and designer analogs: synthesis, stereochemical analysis, and analytical properties, J. Chromatogr. Sci. 32 (1994) 552-564.

[39] S.L. Markantonis, A. Kyroudis, A.H. Beckett, The stereoselective metabolism of dimethylpropion and monomethylpropion, Biochem. Pharmacol. 35 (1985) 529532.

[40] C.L. Hornbeck, J.E. Carrig, R.J. Czarny, Detection of a GC-MS artifact peak as methamphetamine, J. Anal. Toxicol. 17 (1993) 257-263.

[41] M.A. Elsohly, D.F. Stanford, D. Sherman, H. Shah, D. Bernot, C.E. Turner, A procedure for eliminating interferences from ephedrine and related compounds in the GC-MS analysis of amphetamine and methamphetamine, J. Anal. Toxicol. 16 (1992) 109-111.

Please cite this article in press as: A.A.S. Marais, J.B. Laurens, Rapid GC-MS confirmation of amphetamines in urine by extractive acylation, Forensic Sci. Int. (2008), doi:10.1016/j.forsciint.2008.10.021 